\title{
Research on Folk Dance Creation Art of New Generation
}

\author{
Jiangcuo Zhaxi \\ School of Music and Performing Arts \\ Mianyang Teachers' College \\ Mianyang, China 621000
}

\begin{abstract}
The study on dance art of new generation is an exciting topic in the field of dance. "New generation", a distinct generation in China, is a very special population grown up during the stage of reform and opening up after the Cultural Revolution. In the period of new generation, the field of dance art is also becoming complex and diverse, creating various dance works of different styles and contents. There are six aspects in the new generation dance: passionate idealism, strong local flavor and national feelings, formal sense of sublimation and variation, epic themes, traditional culture essence and fashionable "original ecology". The study of national folk dance creation of new generation in different stages aims at better understanding and complying with the development of national folk dance.
\end{abstract}

Keywords-new generation; dance creation; idealism; national feelings; formal sense; original ecology

\section{INTRODUCTION}

The study of "new generation" folk dance art seems to be an exciting topic in the field of dance. As an important artistic phenomenon in the turning period of folk dance in contemporary China, this art trend, which began to appear in the late 1980s, continues to develop and involves various styles in the field of dance. The concept of "new generation" has been clearly defined in the history of modern art. New generation refers to the generation after the Cultural Revolution in the period of reform and opening up. They are so-called 6.8 populations, which mean they were born in $1960 \mathrm{~s}$ and graduated from college in 1980s. They are very special in China. They have spiritual fault with the population born in 1950s. They haven't experienced life of Red Guards and School Graduates. In a sense, age is an important index to define the new generation. So, we can be sure the concept of new generation is also referred to the generation in certain historical period in the art criticism. Therefore, the so-called dance creation of new generation is also dance phenomena presented by this generation, rather than the dance phenomenon of some people ${ }^{1}$. In 1980s, the door of our country was just opened. It was a time that people thoughts were released after being imprisoned strongly for a long time. It was also an age full of freedom thought and ideal. The 90s is a development time of the stock market, the technology of the its background
Internet. It was an era there were poor and riches, that AIDS and drug abuse spread rapidly, materialistic value and utilitarian were in flood. It was also an age that society developed fast and people cared their own value and activity development. The conflict between individual and society made the value pluralism and personal experience worship diffuse in the whole people's values.

Throughout this period, the art of dance has also become complex and diverse. Dance artists created art image with folk dance form, movement, sound and rhythm of music and symbols. In the process of "image materialization", artists created various dance works of different styles and contents through the unique aesthetic psychological connotation, by learning from foreign dance language symbols or the introduction of exotic music materials. Therefore, this paper makes a brief exploration and carding of some representative artists and works in the emergence of the new generation as the research object.

\section{PASSIONATE IDEALISM}

At the turn of 70 s to 80 s, China has experienced a huge historical volatility. It was like a young man awakening from nightmare in the morning. He watched the first rays of morning sun in the sky with his eyes shining with gushing and throbbing longing. Under the guidance of strong modern politics, a lot of Chinese folk dance works were emerged in the fast development of society and economy. The Waves is a special representative works of this period. This works was created in 1980, showing a vigor of fighting with waves with a new look. In the face of the new era, the mentality of 80 s is like a flying petrel in the waves. With confidence, she cried "let the storm come more violent"! This new mood surges made the language style of national folk dance creation change. The arms of dancers imitate petrel flying with the rise and fall of waves. The slow and quick rhythm of petrels and waves show the time difference of flying action between static and dynamic patterns. What a moving sight it is! At the same time, there are many innovations in the works. For example, one dancer plays the role of petrel and wave separately, involving difficult skills into the performance and developing and using the space of lower layer. These innovations made The Waves very special in that period. In this works, Artist Jia Zuoguang extended a broader stage based on national folk dance. This 
stage wasn't set in the prairie, so it has surpassed the scope of traditional dance.

In 1986, Ma Yue created Gallop. It holds the pulse of the new era with prairie dance culture. Like its name, it has a surging momentum. It is a pioneering work of Mongolian dance. What's more, it shows the boiling spiritual image of people after reform and opening up in the 1980s. The performance of principal dancer has always been intertwined with that of other dancers. It corresponds with "one horse gallops in the front" and "ten thousand steeds gallop". It seems that "horse" is in "man", full of vitality. It has both a flurry of speeding momentum and a delight cheer idly in the prairie. In the action, it doesn't use traditional horse step, but designs new horse step according to the works. "After hard thinking, the artist subtly used action of lower limbs with large bead shape to show a trend which cannot be halted. It combines with the action of the upper part twisting and titling backward, which reined the strength. The hands of dancers act the posture of drawing bit, creating a stepping stance (alternating two feet and stepping down forwardly). Then the artist used it as theme action". It can be seen that horse leap in traditional Mongolian folk dance is focused on "momentum", "dynamics", "strength" and "imposing manner". To certain extent, it reflects the importance of action in dance works. It is worth noting that the artist didn't separate from basic cultural features of Mongolian folk dance in grasping the features of Mongolian folk dance. He used traditional Mongolian clothing, distinctive Mongolian dance vocabulary, and the typical three-section structure. More importantly, he integrated mentality and artistic image of modern people in the Mongolian traditional folk culture.

Some similar works include Sun Longkui's Late Spring. In these works, artists began to hold a higher vision in the spirit of folk dance. With the pursuit of being alike in spirit, the use of form and change were more freely and orderly. After the dance vocational education has developed to certain degree in China, the dance works created by teaching began to emerge, and gradually rose.

\section{RICH LOCAL FLAVOR AND NATIONAL FEELINGS}

In late $80 \mathrm{~s}$, a blast of bold and elated yellow-earth wind appeared in literature, music, film and other fields, creating a spirit totem of national backbone. It is no exception in field of dance. Chinese folk dance creation has become an eyecatching focus in this period. The main works of this period are Love of Daughters and Sons of the Yellow River, From the Yellow River, Yellow Earth and Yangko Dancer. The representative artists include Zhang Jigang. After reform and opening up, "national folk music has aroused long lost country flavor. With the integration elements of modern dance, disco, jazz and break dance, it produced new dance movement which is difficult to describe by language" ${ }^{3}$. The combination of simple and plain traditional dance culture and novel modern dance culture has spanned the regional space and the time concept of social development. The combination of each other

\footnotetext{
Ma Wei. One horse gallop in the front and ten thousand steeds gallop - Dance Art Features of "Gallop". Dance.1985 (2).

Fan Zhijun. Love of Daughters and Sons of the Yellow River in Traditional Beauty. Dance, 1987 (11): 73.
}

brings a sense of surprise, but also brings about the collision between different cultures. However, the novel exotic dance culture is not the focus of these artists who stop after getting a few elements from popular modern dances. The standpoint of their works was to return and represent the yellow earth culture. This kind of return and reappearance had a strong impact on the chaotic cultural background at that time. It reflected the conscious desire that the cultural and artistic creators would not be lost and tried to explore their own cultural matrix. Because of this, Yu Ping regarded it as the second impact wave in field of dance in the new period. "The first impact wave, dance drama, Flower Rain in Silk Road in the new period has resuscitated the static language of traditional dance. The second impact wave, folk dance evening party, Love of Daughters and Sons of the Yellow River has carried forward the life details of traditional dance" 4

From the Yellow River shaped a group of images from the Yellow River. With dynamic dance, the drums and yangko have left a great impression. With firm and stable steps, we can see the forward steps of Chinese carrying profound tradition and the shadow moving between the history and reality. These representative works show the model of academism in folk dance creation. The stable and firm movement style and aesthetic characteristics extracted from drum and yangko has sublimated the exemplary meaning of folk dance tradition.

"It can be seen that Zhang Jigang, as a young director, has present dance - youth art to people. But his aim was not to arouse the vitality of youth but to meet their nostalgic feelings", "Moving by return, the culture of Yellow River and yellow earth with strong national feelings and local flavor has made us deeply experience the tenacious spirit power supporting thousands of years of Chinese civilization. When the culture was thrown into the whirlpool of modern society in China, she also has a tragic atmosphere hard to get ride" 6 . Chinese famous director Zhang Jigang ever said: his idea is on "rice" (theme) but it becomes "wine" after putting on stage by dance. It is a vivid metaphor. It is a qualitative process by changing from "rice" to "wine". "Rice" is a culture, while "wine" is an art. The fragrance of "wine" is inseparable from the mellow "rice". Zhang Jigang's creation put national folk dance creation of academism to a peak, especially the humanistic value of Han folk dance culture in his works, which is very prominent in the depth of thinking and the height of view. In addition, with the active development of folk dance in the late 90 s and the early 80 s, the trend of diversification was becoming more and more obvious, which leads to the division of the types of folk dance creation, and also makes dance creation into an awkward and complex situation.

\footnotetext{
4 Yu Ping. Third Shock Waves: the Rise of "Academism" Dance Creation. Guangming Daily, Feb. 1, 1990.

Yu Ping. From Song and Dance of the Young to "To My Parents". New Cultural Newspaper, Dec. 15, 1991.

$6 \quad$ Xu Rui. Aesthetics and Consciousness of Contemporary Chinese Folk Dance Creation. Shanghai: Shanghai Music Publishing House, Nov. 2014, P106, L6.
} 


\section{The Sublimation AND VARIATION OF SENSE OF FORM $^{7}$}

When "Zhang Jigang et. al." has deeply sunk into the soil of traditional culture, some other people floated up to a more free creation space - pursuing the highly artistic sense of form. During this period, the representative works are Soul of Peacock, A Green Leaf and Lie $\cdot$ Lie $\cdot$ Lie, represented by Yang Liping and Ding Wei.

Soul of Peacock was created in 1986. With qualitative change, Yang Liping broke through the traditional category of folk dance, lightening the stage of folk dance with folk culture. "From her poetic dancing arms and floating fly and stable hovering, we can see both a beautiful peacock and a dancing girl of Dai nationality (or dancer herself) who is expressing his persistent pursuit for a better world. This dance has fully reflected subjective consciousness and independent spirit of the artist, so it has created such a distinctive dance art image of beauty" $^{8}$. Yang Liping fully developed her body revolving around this image and created her own dance language. Especially, her waving arms and exaggerated body curvature became her symbolic dance language and form.

Different from the individual dance form of Yang Liping, A Green Leaf cut dance apart from its historical tradition from content and form. We can only feel a new artistic expression in the form of looming folk dance. The soft dancing of A Green Leaf is consistent with Jiaozhou yangko with soft flying step. The image of "green leaf" is so active and lively in the "flowing" yangko. From this work, we can also see that the national dance teaching of academic school has reached a high level in the exploration of the deep level of movement. At the same time, we can see the influence of modern dance training on the creative action and the dancer's body movements, which shows that the dancers have a purposeful and conscious pursuit of the sense of form.

\section{EPIC THEMES}

In the middle and late 90s, a lot of dance works began to reflect the culture of the Yellow River and the spirit of the Chinese nation, mainly including the Yellow River, Dongfanghong, and Preface to the Red River Valley. Different from the works of the early 90 s and the late 80 s, in order to get rid of the theme of folk customs, artists made a bold processing and recombined the material movements at this stage. They combined dance with grand symphonic music, and blended structure and form into a harmonious whole, which has showed a magnificent chapter of the struggling course of our nation and brought a thrilling art power. Therefore, the works of the former period are of local favor; the works of the later period show noble spiritual temperament. With the development of the times, dance creation should also adapt to changes in society and the requirements of the times.

7 Xu Rui. Aesthetics and Consciousness of Contemporary Chinese Folk Dance Creation. Shanghai: Shanghai Music Publishing House. Nov. 2014, P107.

8 Wang Kefen, Long Yinpei. Development History of Modern Chinese Dance. Beijing: People's Music Publishing House, 1999, P417.
Preface to the Red River Valley is not only a reflection of Tibetan historical and cultural traditions, but also a reverence for the unique cultural values of Tibetan people. In the works Tibetan folk dance has an obvious variation in such atmosphere of music. Opening and closing amplitudes of action are so exaggerated. The strong rhythmic and heavy traditional style of Tibetan dance has also been replaced by fluid dance style. The grand theme described in the works seems to be far away from the flavor of folk culture. In fact, it is the transcendence of folk culture that makes people feel the specific moving plots and abstract emotional power of the works. However, the teaching of national folk dance of academism has peeled the connotation of folk culture off in a certain extent, so that it is easy to put action purely on technical level as material of art expression in creation. It is difficult to control the distance between art connotation and folk culture. Obviously, this grand-themed works is a reflection of the pursuit of diversity in contemporary folk dance creation and the exposure of a national spirit in creative practice.

\section{THE CONTINUED DEVELOPMENT OF TRADITIONAL CUlture EsSENCE}

Folk dance has strong vitality. It is the source in creating works with traditional cultural temperament. Therefore, although contemporary folk dance creation has diversified innovations, the inheritance and development of the essence of traditional culture is still the mainstream. Uygur folk dance Bowl Dance was created in 1997. It is a typical example that traditional dance culture is presented on contemporary stage. With no profound expression of art, the works only beautify the form of Uygur folk dance to the extreme. In a simple way, it is presented on the stage, to convey a pleasing pleasure. The beauty displayed in the works is not only from its external form, but also comes from the deeper connotation of traditional culture. The simple steps, the tender eyes and the slight lift of shoulder are associated with traditional culture of profound implication. Of course, it isn't only stay in old traditional culture. It makes full use of stage technologies and dance training level to greatly improve the level of performance. The visual impact of modern aestheticism gives the works with a great aesthetic atmosphere and cultural charm.

Female Cousin is Yi dance works directed by the famous director Ma Lin in the same period. But the works is not the simple continuation of the tradition. It has shaped characters and released emotions through various dramatic conflicts. It drew material from an old Yi marriage customs and legend: a brother carried his younger female cousin on the back and sent her to her future husband's family to get married. But surprisingly they were brought up together and loved each other. The destiny has made fun of them. The works is unfolded with this dramatic emotional conflict as core content of art expression. Although the movement style of $\mathrm{Yi}$ folk dance continues in the works, the traditional culture rendered by has become the background of the tragedy of love. We are no longer concerned with the national style of the dance itself, but moved by the fate of the characters. In the face of such folk dance, modern audiences have become the hunters for novelty 
in traditional culture. Except for being moved, there is also a sense of superiority and happiness in the free love of new era.

On the basis of traditional folk dance, it is a prominent and common problem to create a new stage dance language, and to express the connotation of traditional culture with this kind of language. Therefore, it is necessary for the artists to treat it carefully and handle it seriously.

\section{FASHIONABLE ORIGINAL ECOLOGY}

Under the promotion of market economy at the beginning of the century, market-oriented literary route is stately recognized by more and more people. It is the direct reason accelerating the development of folk dance toward fashion. It has caused some controversies about fashion, reflection of modern literary and art theory and culture crisis. Admittedly, the display of new dance elements and sensory entertainment makes folk dance more "good-looking", and brings audiences with a new fashion feeling and dazzling audio-visual enjoyment. In fact, this is the original intention of the creators. After art has developed relationship of "nurturing" and "being nurtured" with market. Artists have too much helplessness and temptation and they hover between them. We can see that they have reached a relatively high level in the production of fashionable folk dance, such as, excellent show in Bibo Peacock. Of course, it is the convention of market operation. Large production and high investment can ensure good production and good market return on investment. However, at the same time, the influence of fashion began to extend to our national folk dance creation indiscriminately, which made the grade of culture decline.

However, not all folk dance creators choose to follow the modern fashion variation of the commodity market. The snobbish commodity market sometimes follows the creators that stick to the traditional values. In 2002, Yang Liping, a famous Chinese dancer, launched a song and dance collection Dynamic Yunnan with a lot of originally ecological folk dances, which enabled people to re-recognize the artistic spirit and value of traditional folk dance. In the song and dance evening party, "original ecology" became an important concept. Yang Liping explained: "it is an expression form closest to nature and human. Farmers believe that everything has a spirit, and people need to communicate with heaven and earth, all things and gods. And dance is the only way people communicate with all things..."9 . On this point, $\mathrm{Zi}$ Huajun has defined it from the height of theory: "the culture of 'original ecology' has a strict definition, namely, the primary form (basically without processing and packaging), the original form (not separated from the natural and human environment of its formation and development), and the natural or quasinatural transmission. It is the source of water and root of wood - shared by both artists and common people. Obliviously, Dynamic Yunnan is a stage art. It has condensed the personalized creation of artist and stage packaging of certain extent, rather than 'adobe' of folk art. This shows that "original ecology" is a complete system of culture and style. It is not only related to the heritors, but more importantly, maintains its original form and natural way of transmission in its original environment. Indeed, the speculation and fashion prevail in the literature and art market at the beginning of the century. There are too many national folk dance performances making people disappointed. Dynamic Yunnan like a stream flows into our hearts.

Another problem worth every one of us to think about is that we should objectively and rationally treat Chinese national folk dance creation when re-recognizing the form of original ecology. It is a long way with both inheritance and innovation.

\section{CONCLUSION}

The six aspects mentioned above are the carding of the dance creation of the new national folk dance at different stages in China. The purpose is to better understand and respect the regularity of the development of national folk dance creation. Chinese civilization has continued for thousands of years of, and folk dance is one of the most important parts. In the multicultural environment brought by globalization, the author has reviewed and combined the development course of folk dance in new China, and deconstructed and analyzed the aesthetic form and cultural connotation. It enables us to clarify the concept and the development rule of national folk music. Thus, it gives a correct and rational answer to the pursuit and choice of national folk dance creation for new generation in modern China.

\section{REFERENCES}

[1] Guo Tian, Li Ping. Style and Taboo. Beijing: Chinese Book Publishing House. May 2015.

[2] Institute of Dance Education, Beijing Dance Academy. Criticism on Dance Creation. Beijing: Minzu University of China Press, May 2015.

[3] Xu Rui. Aesthetics and Consciousness of Contemporary Chinese Folk Dance Creation. Shanghai: Shanghai Music Publishing House, Nov. 2014.

[4] Yu Ping. Poetic Dance Creation. Beijing: Renmin University of China Press, First Edition, Jun. 2015.

[5] Li Xu, Zhang Shouhe, et al. Dance Creation Research. Beijing: Higher Education Press. Oct. 2009.

[6] Mu Yu. Chinese Contemporary Dance Creation and Research. Beijing: China Federation of Literary and Art Publishing House, Oct. 2009.

[7] Jin Qiu. Dance Creation. Beijing: Higher Education Press, Aug. 2012.

[8] Huang Mingzhu. Chinese Dance Art Appreciation Guide. Shanghai: Shanghai Music Publishing House, Jan. 2001.

[9] Wang Mei. Research on Dance Scheduling. Nanjing: Jiangsu Phoenix Literature and Art Publishing House. Dec. 2014.

[10] Zhu Liyuan. Contemporary Western Literary Theory. Shanghai: East China Normal University Press, Apr. 2005.

[11] Lv Yisheng. Dance Aesthetics. Beijing: Minzu University of China Press, Sep. 2011.

[12] Yu Ping. Chinese Dance Art. Beijing: China Music Publishing House, Nov. 2009

[13] Wang Mei. Modern Dance Creation of Traditional Dance. Shanghai: Shanghai Music Publishing House, Sep. 2017

9 Sina, www.sina.com.cn, Sina Entertainment, Dynamic Yunnan. 